\title{
Protagonismo Feminino no Prêmio Design Museu da Casa Brasileira: análise dos anos 2017 a 2019
}

\author{
Raquel Bosso Romano; \\ Valdirene Aparecida Vieira Nunes; \\ Mônica Cristina de Moura
}

resumo:

O presente artigo é parte de uma pesquisa de mestrado em design que aborda o protagonismo feminino no design brasileiro fundamentado em estudos do feminismo. Sobre o tema, sabemos que a desigualdade de gênero é um problema social que se manifesta no mercado de trabalho mundialmente de diversas formas, como exemplo as diferenças salariais, a segregação na divisão sexual no trabalho e as múltiplas jornadas em que o feminino é submetido. Assim, inserido nesta temática, o artigo busca compreender como as mulheres interagem com o design profissionalmente e se as premiações da área representam um espaço de dificuldades para as profissionais. O método adotado foi de caráter qualitativo e quantitativo, com aplicação da revisão bibliográfica e do estudo de caso. Para o presente estudo aqui posto elegeu O Prêmio Design Museu da Casa Brasileira (20172019) como amostra para o levantamento da presença feminina entre os autores e os jurados presentes na premiação. Nesse sentido, constatou-se que o número de mulheres nesses espaços vem crescendo, contudo ainda é possível verificar alguns impasses para o público feminino. 


\section{Introdução}

Como afirmou Simone de Beauvoir (1970) as mulheres e os homens nunca partilharam o mundo com igualdade de condições, embora atualmente essas situações estejam evoluindo, as mulheres ainda arcam com impasses. Por exemplo, no mercado de trabalho os homens brancos possuem condições mais vantajosas, salários mais altos, maiores possibilidades de êxito, ocupam maior número de lugares na indústria e na política. Ao contrário das mulheres que dentro do universo de trabalho quase em sua totalidade exercem jornada dupla, devido ao estigma de que as funções do lar são inerentes às mulheres.

Considerando a inevitabilidade dos designers estarem sujeitos às ideias e influências de seu contexto social, faz-se necessário compreender o modo como as mulheres interagem profissionalmente com o design e como essa interação é registrada, baseado em estudos do feminismo. (BUCKLEY, 1986). Com a expansão da participação do feminino e a abertura das universidades para a entrada de mulheres na academia, ocorreu também o maior interesse em pesquisas relacionadas aos problemas como discriminação social e cultural da mulher, bem como sua exclusão das esferas de poder. $\mathrm{O}$ que favoreceu a redescoberta da atuação feminina por campos que até então eram resistentes ao tema. Algumas autoras, como Cheryl Buckley (1986), Giselle Safar e Marcelina Almeida (2014), afirmam que as abordagens com a temática da reflexão de gênero e feminismo no design são recentes. Apesar disso, não devem ser uma questão secundária uma vez que as mulheres ainda enfrentam condições desiguais nesse campo, faz jus pesquisar as barreiras impostas para com as mulheres que impedem sua equidade. Alguns desses impasses presentes no cotidiano das profissionais são citados por estudiosas do tema, como: a falta de referências e citações femininas na história do design, pouco reconhecimento profissional, negacionismos dos seus feitos, postos subalternos, salários inferiores entre outros.

O presente artigo aborda as questões sociais relativas ao gênero no meio das premiações da área do design de produto. Mediante uma pesquisa qualitativa e quantitativa, com aplicação da revisão bibliográfica e do estudo de caso. Realizada no cenário do Prêmio Design Museu da Casa Brasileira (MCB) entre os anos de 2017 e 2019. Investigando a participação feminina na composição da banca de jurados da premiação e na autoria dos projetos selecionados e divulgados nos catálogos do Prêmio. Para além do recorte de gênero, foi possível no grupo de jurados, verificar a ocorrência de mulheres negras na composição do júri. Assim, buscamos compreender e dialogar a respeito da interação das profissionais na premiação, se esse é um espaço de desigualdade para as mulheres uma vez que possuem importância na área do design.

\section{Premiações em Design: um campo de reconhecimentos ou inquietações para com os participes?}

Os prêmios de design além de oferecerem visibilidade e reconhecimento para os profissionais envolvidos, também contribuem para a construção de um amplo registro histórico da produção brasileira na área. Ao analisar os objetos selecionados para compor os catálogos das premiações, conseguimos refletir sobre "as preocupações do design ao longo do tempo na busca por apresentar soluções aos anseios da sociedade de sua época." (CARNASCIALI, 2014, p.123). Por outro lado, segundo Joice Joppert Leal (2010), as premiações também despertam a atenção da mídia e o interesse de instituições ao design, aumentam as vendas, proporcionam a credibilidade e valorização do profissional e da marca, criando a oportunidade de divulgação de produtos com a confiabilidade do consumidor. Ademais, conferem aos produtos e aos profissionais que os desenvolve um diferencial, destacando a sua qualidade e proporcionando um aumento de seu consumo. (MOURA, 2015).

Desta forma, condiciona visibilidade para os participantes, como também pela obra apresentada contribui com o construto histórico dos futuros designers, igualmente com a área de forma ampla, nos campos sociais e industriais, uma vez que a referência da criação torna-se exemplo projetuais. 
Neste sentido, as contribuições da autora Cyntia Sousa (2019) alegam que, muitas vezes, os produtos vencedores das premiações passam a constituir o acervo de design das instituições promotoras, ou são destinados aos museus parceiros. O acesso a essas informações corrobora para a percepção de como os critérios de avaliação adotados se materializam nos produtos vencedores de tais premiações. Também de como as características e soluções encontradas pelos designers refletem as demandas de um momento e da sociedade. Assim, esses acervos e catálogos constituem "um importante referencial para a construção e atualização permanente do repertório, tanto de docentes quanto de estudantes de design." (SOUSA, 2019, p.231). Esse referencial construído a partir de uma curadoria especializada situa, segundo Cyntia Sousa (2019), na fronteira de uma visão idealizada de futuro e da contribuição do design para a sua concretização. Sendo papel intrínseco de o design permanecer atento à cultura e à sociedade, ocupa então as atribuições de manifestar as suas contradições, costumes e realidades desses meios através dos objetos que configura.

O design seria, antes de tudo, instrumento para a materialização e perpetuação de ideologias, de valores predominantes em uma sociedade, ou seja, o designer, conscientemente ou não, re-produziria realidades e moldaria indivíduos por intermédio dos objetos que configura. (BOMFIM, 1997, p.32)

Não obstante, Ethel Leon (2012) observa que no cenário brasileiro as exposições de objetos de design premiados tendem a remeter mais aos seus valores mercadológicos ao invés de possibilitar reflexões mais profundas, como o destaque ao fazer do projeto, enquanto atividade produtiva de alternativas e possibilidades. Para a jornalista, as exposições poderiam mostrar a um público mais amplo a reflexão sobre o cotidiano, como cita no posicionamento de François Burkhardt (1989), sobre o papel dos museus, ao destacar sua importância para além da recuperação de fatos históricos, mas um museu apontado para o futuro que opera em campos que possibilitem instigar no desenvolvimento do que acontece e que integre uma afirmação e um destino para o futuro, sem fórmulas e sim com vias abertas para que os participes as concluam.

\subsection{O Prêmio Design Museu da Casa Brasileira}

Esse artigo possui como objeto de estudo o Prêmio Design Museu da Casa Brasileira. Considerado uma das premiações de design mais respeitadas e tradicionais do país, realizada desde 1986. O objetivo do prêmio é promover o ofício do designer, estimular a adoção de soluções de arte e tecnologias brasileiras, além de revelar novos talentos. Os critérios de seleção incluem aspectos como a qualidade estética, a criatividade e a funcionalidade. (LEAL, 2012). Transmite anualmente um panorama da produção nacional com categorias que englobam o Design de Produto, a produção escrita (acadêmica e editorial ligadas ao design) e o Concurso do Cartaz. O prêmio é executado em conjunto com o Museu da Casa Brasileira e a instituição da Secretaria da Cultura e Economia Criativa do Estado de São Paulo.

Anualmente recebe a média de setecentas inscrições advindas de todo o país. A premiação de design de produtos abrange oito categorias, sendo elas: mobiliário, utensílios, iluminação, têxteis, equipamentos eletroeletrônicos, de construção e de transporte. Cada uma delas permite a participação tanto de produtos já desenvolvidos e lançados como de protótipos. Os trabalhos selecionados pelo júri compõem os catálogos de cada edição, e neles é possível reunir informações que compreendem um amplo material de pesquisa sobre o design brasileiro.

$\mathrm{Na} 33^{\circ}$ edição do prêmio, no ano de 2019 , ocorreram algumas transformações significativas, como no caso do Concurso do Cartaz, realizado com o intuito de incentivar o design gráfico. Na edição pontuada a comissão julgadora, coordenada por Gustavo Piqueira, percebeu uma significativa presença de peças nas quais predominaram referências às questões sociais e ao cenário político brasileiro. Temas que não costumavam despontar no concurso em edições anteriores. Os cartazes premiados nesta edição atenderam além dos requisitos habituais de seleção, também ao comprometimento em discutir o cenário sociopolítico do Brasil. (Museu da Casa Brasileira, 2019).

Dessa forma, observando o potencial do prêmio em um contexto delimitado, surgiram questionamentos a respeito do protagonismo e participação feminina nas premiações de design. 


\section{Protagonismo Feminino no Design?}

Até a década de 60, quando o movimento feminista impulsionou os estudos de gênero, eram ínfimas as referências femininas na história do design. Ocorrendo a partir dos anos 90, o aumento da demanda por posicionamento crítico da historiografia da área. Nesse momento decorrem estudos de gênero em design voltados à busca de registros históricos das mulheres profissionais e suas contribuições. (ANDRADE \& REBELLO, 2008). Apesar das poucas citações e referências de participação feminina, Cheryl Buckley (1986) conta que as mulheres se envolveram com o design de diversas maneiras, como profissionais e teóricas. No entanto, a literatura sobre a história, teoria e prática do design nos leva a acreditar o contrário. Segundo a autora, essas omissões não são acidentais, mas sim consequência de métodos historiográficos específicos. Os historiadores ocultaram as mulheres e as poucas que aparecem são definidas pelo seu gênero, relegadas ao segundo plano, subjugadas sob o nome do marido, pai ou irmão.

Outro fator relevante é a questão da segregação da raça, no documento intitulado Guia de enfrentamento ao racismo institucional a descriminação ${ }^{1}$, resultante de uma construção coletiva que ajuntou organizações feministas e antirracistas brasileiras, o Governo Federal e o Sistema das Nações Unidas no país, objetivando contribuir para com o enfrentamento do racismo Institucional, definiu em seus objetivos planos de ações e indicadores que permitam o enfrentamento do Racismo Institucional. Compreende-se assim, que a equidade na participação das mulheres negras em diversas áreas faz jus em nosso país, uma vez que, estas infelizmente ainda representam minorias no campo do design em suas diversas vertentes. Essa falta de mulheres negras na área é salientada brevemente por Pat Kirkham (2002) quando observa na publicação In a "Man's World" Women Industrial Designers que de todas as designers levantadas apenas uma era negra, ressaltando uma terrível falta de diversidade racial no campo do design industrial.

Face à baixa incorporação ainda da equidade das mulheres negras, e frente ao racismo institucional nos processos de trabalho, compreender a participação do gênero feminino negras na representatividade no âmbito da participação como júri no Prêmio Design Museu da Casa Brasileira é de fundamental importância na potencialização da equidade, que segundo as diretrizes do Guia de enfrentamento ao racismo institucional a descriminação torna-se uma ação de cunho social no que se refere ao monitoramento, avaliação e superação do racismo institucional, "frente ao ainda reduzido número de experiências prévias de estratégias para a erradicação desse fenômeno, na expectativa de contribuir para que organizações governamentais e sociais passem a adotar mecanismos efetivos de prevenção, monitoramento, avaliação e superação do racismo institucional”.

Ao tratarmos do gênero feminino, decerto não podemos continuar ignorando as contribuições das profissionais do design presente na nossa cultura. Ana Beatriz Andrade e Ana Maria Rebello (2008) declaram que no Brasil as designers estiveram intimamente ligadas a implantação da área. Citam Lina Bo Bardi que participou da criação e coordenou o Instituto de Arte Contemporânea do Museu de Artes de São Paulo, primeiro núcleo experimental voltado ao ensino do Design. Além de Carmen Portinho, que aparece como organizadora da segunda tentativa de implementação do ensino do Design no país com o projeto da Escola de Criação, e da Forma do Museu de Arte Moderna do Rio de Janeiro.

Além da questão da falta de protagonismo feminino, as autoras estudadas indicam a divisão sexual do trabalho como mais uma das dificuldades vivenciadas pelas mulheres e que se repete no campo do design. Essa segregação pode ser observada na área, por exemplo, na Bauhaus (1919-1933), centro de design e arquitetura de grande impacto no design industrial e gráfico do século XX. A escola, segundo Isabel Campi (2010), promovia a igualdade entre os estudantes e a não distinção de raça e gênero. Apesar disso na realidade da escola as mulheres eram majoritariamente influenciadas a se inscrever na área têxtil. Técnica que, consoante com Marisa Vadillo (2009), era associada a virtudes que foram impostas às mulheres como paciência, calma e obediência, além de ser realizada tradicionalmente nos espaços domésticos. Isto é, mesmo quando as mulheres foram possibilitadas de ingressar nas academias de design, foram simultaneamente limitadas a manter-se na área que foi reservada a elas.

1 FONTE: http://www.onumulheres.org.br/wp-content/uploads/2013/12/Guia-de-enfrentamento-ao-racismoinstitucional.pdf. Acesso em: 10 de ago. de 2020. 
$\mathrm{Na}$ atualidade do campo do design a divisão de áreas consideradas femininas persiste, Schneider (2010) indica algumas delas, como: moda, decoração, cerâmica e joalheira. As segmentações citadas por Schneider (2010) concordam com as de Cheryl Buckley (1986). A professora afirma que as mulheres são consideradas naturalmente preparadas para certas áreas de produção do design, como as artes decorativas, joalheria, bordados, tecelagem e cerâmica. Além desses segmentos, Margaret Bruce (1985) também destaca que muitas mulheres direcionam suas carreiras ao ambiente da educação e pesquisa em design, devido a maior flexibilidade de horários de trabalho, o que as auxiliaria em suas múltiplas jornadas. Essas são consequências de responsabilidades atribuídas às mulheres ao longo da história como: cuidar da família, criar os filhos, gerenciar e cuidar da casa, entre outras.

No cenário das premiações, Margaret Bruce (1990) declara que a maior parte dos prêmios são atribuídos aos homens. Além disso, Alice Hetzel (2016), em sua dissertação de mestrado a respeito das mulheres no design gráfico, expõe como esses eventos estão entre os espaços em que o público feminino mais enfrenta impasses. Uma vez que são de grande importância para as profissionais, devido à visibilidade proporcionada por eles que se relaciona com o reconhecimento profissional.

Com base no breve contexto histórico do protagonismo feminino na área do design, iremos discorrer sobre a participação feminina no Prêmio Design Museu da Casa Brasileira, a partir de uma pesquisa quantitativa realizada nos últimos três anos do prêmio, entre 2017 e 2019. O levantamento foi feito tanto no número de autores dos projetos como no júri selecionado para cada categoria e os resultados integram uma pesquisa de mestrado realizada no cenário do design de produto e do design gráfico.

\section{Método Utilizado}

O método adotado tem caráter misto e envolve as abordagens qualitativa e quantitativa, abrangem as modalidades de pesquisa bibliográfica, documental e o estudo de caso. A partir da análise documental dos catálogos disponíveis online das premiações, foram realizados os levantamentos quantitativos do Prêmio Design Museu da Casa Brasileira entre os anos de 2017 e 2019. A fim de verificar a participação feminina na premiação tanto como autoras dos projetos como na composição do júri do Prêmio.

Como pontuado, o conteúdo dos catálogos constitui uma significativa fonte de informação e pesquisa. Isso, pois incluem toda a trajetória do prêmio naquele período, o processo de julgamento dos projetos, os autores e premiados da edição, bem como a composição do júri. Portanto permitiram que o levantamento de nomes culturamente atrelados ao feminino e ao masculino fosse possível. Reforçamos que o levantamento ocorreu com base nos nomes citados nos catálogos e quando houve dúvidas a respeito do gênero normalmente ligado ao nome, o mesmo foi verificado em sites de busca. Ademais, os catálogos analisados disponibilizam fotos com todos os integrantes do júri em cada edição. Dessa forma, verificamos o número de mulheres negras presente na composição da banca de jurados. A avaliação foi realizada através da heteroatribuição, em que o observador define a categoria que pertence o observado baseado nas características visíveis de classificação racial. (PETRUCCELLI \& SABOIA, 2013). Até o momento, o levantamento a partir do recorte racial foi possível apenas na composição dos jurados.

Após a coleta dos dados, os resultados foram analisados com base nos seguintes questionamentos:

- O júri apresenta equidade entre o gênero feminino e masculino?

- As categorias que possuem mais mulheres juradas também possuem mais mulheres com prêmios?

- No decorrer dos anos podemos visualizar aumento de participação feminina tanto no júri como nos autores dos projetos?

- Entre os autores dos projetos premiados observa-se a equidade entre o gênero feminino e masculino?

- Existem mulheres negras integrando o grupo de jurados? 
Sendo assim, depois da análise baseada nesses questionamentos foram elaborados infográficos e quadros a fim de transmitir os resultados e facilitar a compreensão. Ademais, como essa pesquisa aborda o protagonismo feminino no design, foi escolhido adotar o procedimento de tratar por nome e sobrenome sempre que forem introduzidas pessoas do gênero feminino no discurso, ao serem citadas de modo direto. Esta atitude tem como finalidade promover o reconhecimento das mulheres intelectuais e acadêmicas dos assuntos considerados, além de evidenciar a predominância de citações femininas nessa pesquisa.

\section{Resultados}

“Para pensar soluções para uma realidade, devemos tirá-la da invisibilidade.” (RIBEIRO, 2019, p.30).

A composição dos jurados e coordenadores selecionados para a banca de avaliação do Prêmio Design Museu da Casa Brasileira possuiu em média 53 pessoas em cada ano, no período de 2017 a 2019. Ao analisarmos o júri em sua totalidade, refletindo apenas sobre o gênero dos envolvidos, (Concurso Cartaz, Concurso de Produtos e Trabalhos Escritos) percebemos que as mulheres juradas estão em constante aumento. Além disso, as mulheres são maioria na composição total de jurados em todos os anos analisados. Porém, ao separamos o júri por suas respectivas categorias (cartazes, produtos e trabalhos escritos) constata-se que o campo de trabalhos escritos detém o maior número de jurados e também a maior parcela de nomes femininos presentes em todo o júri. (Tabela 1).

Tabela 1 - Jurados do Prêmio Design Museu da Casa Brasileira

\begin{tabular}{|c|cc|cc|cc|cc|}
\cline { 2 - 9 } \multicolumn{1}{c|}{} & \multicolumn{2}{c|}{ CARTAZ } & \multicolumn{2}{c|}{ PRODUTOS } & \multicolumn{2}{c|}{ TRABALHOS ESCRITOS } & \multicolumn{2}{c|}{ TOTAL } \\
\cline { 2 - 9 } \multicolumn{1}{c|}{} & Fem. & Masc. & Fem. & Masc. & Fem. & Masc. & Fem. & Masc. \\
\hline 2017 & 1 & 4 & 4 & 13 & 23 & 10 & 28 & 27 \\
\hline 2018 & 1 & 4 & 8 & 9 & 20 & 12 & 29 & 25 \\
2019 & 2 & 3 & 7 & 9 & 17 & 7 & 33 & 17 \\
\hline
\end{tabular}

Os gráficos seguintes (Gráfico 1 e 2) expõem o total de jurados dividido pelo gênero feminino e masculino para as categorias de cartaz e produto nos últimos três anos. Com base no questionamento a respeito da equidade entre os gêneros no júri, os resultados revelam que nesses âmbitos a diferença diminuiu consideravelmente, e possivelmente, caminha rumo a uma equidade de gênero dos participantes da banca avaliadora. 
Gráfico 1 - Júri da Categoria de Cartazes

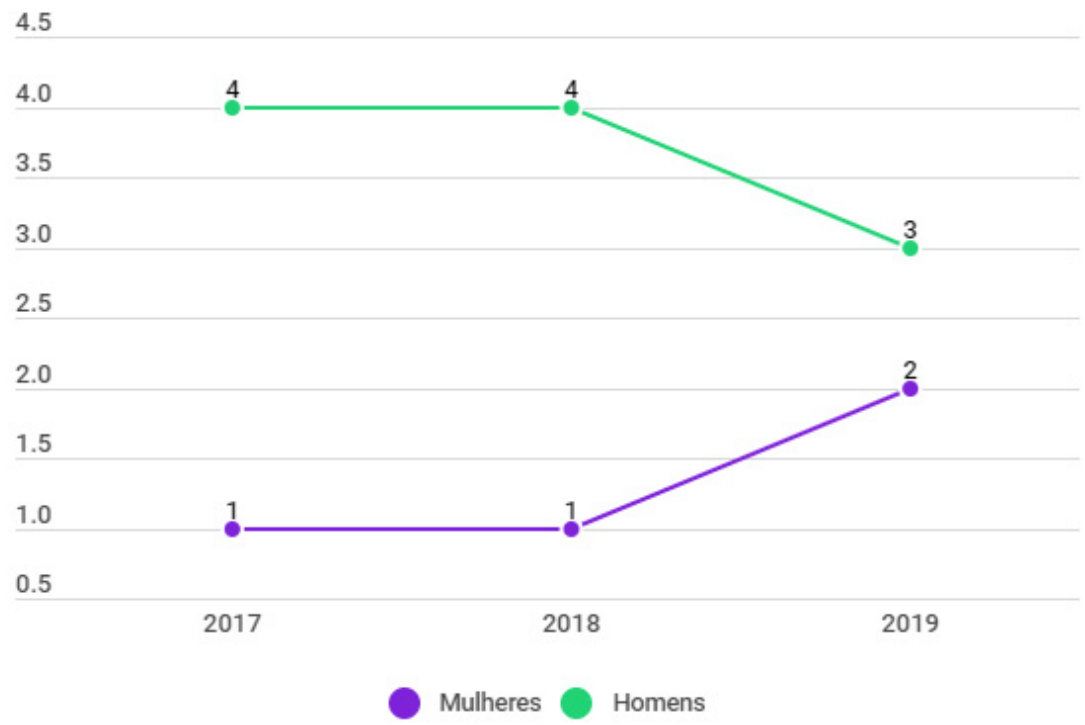

Gráfico 2 - Júri da Categoria de Produto

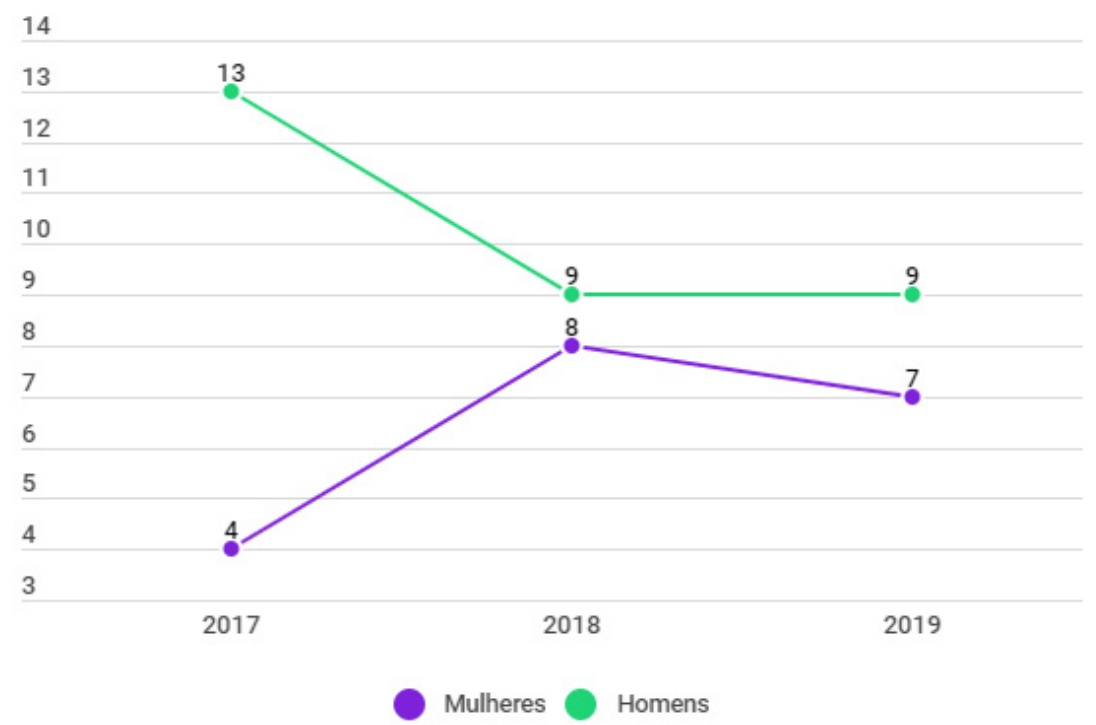

Além disto, com o intuito de assimilar como a prevalência de um gênero no júri se relacionaria com o resultado dos autores selecionados para o Prêmio, dividimos também as subcategorias de Produto, sendo elas: Construção, Eletroeletrônicos, Iluminação, Mobiliário, Têxteis, Transporte e Utensílios, como demonstrado no Gráfico 3. Assim, contemplamos que os campos de Iluminação e Têxteis se relacionam no sentido de que o primeiro não apresenta juradas mulheres e o segundo não possui jurados homens, em nenhuma das edições analisadas. A categoria de Eletroeletrônicos também retrata uma diferença considerável entre os gêneros. 
Gráfico 3 - Divisão entre o gênero feminino e masculino no júri da Categoria de Produto
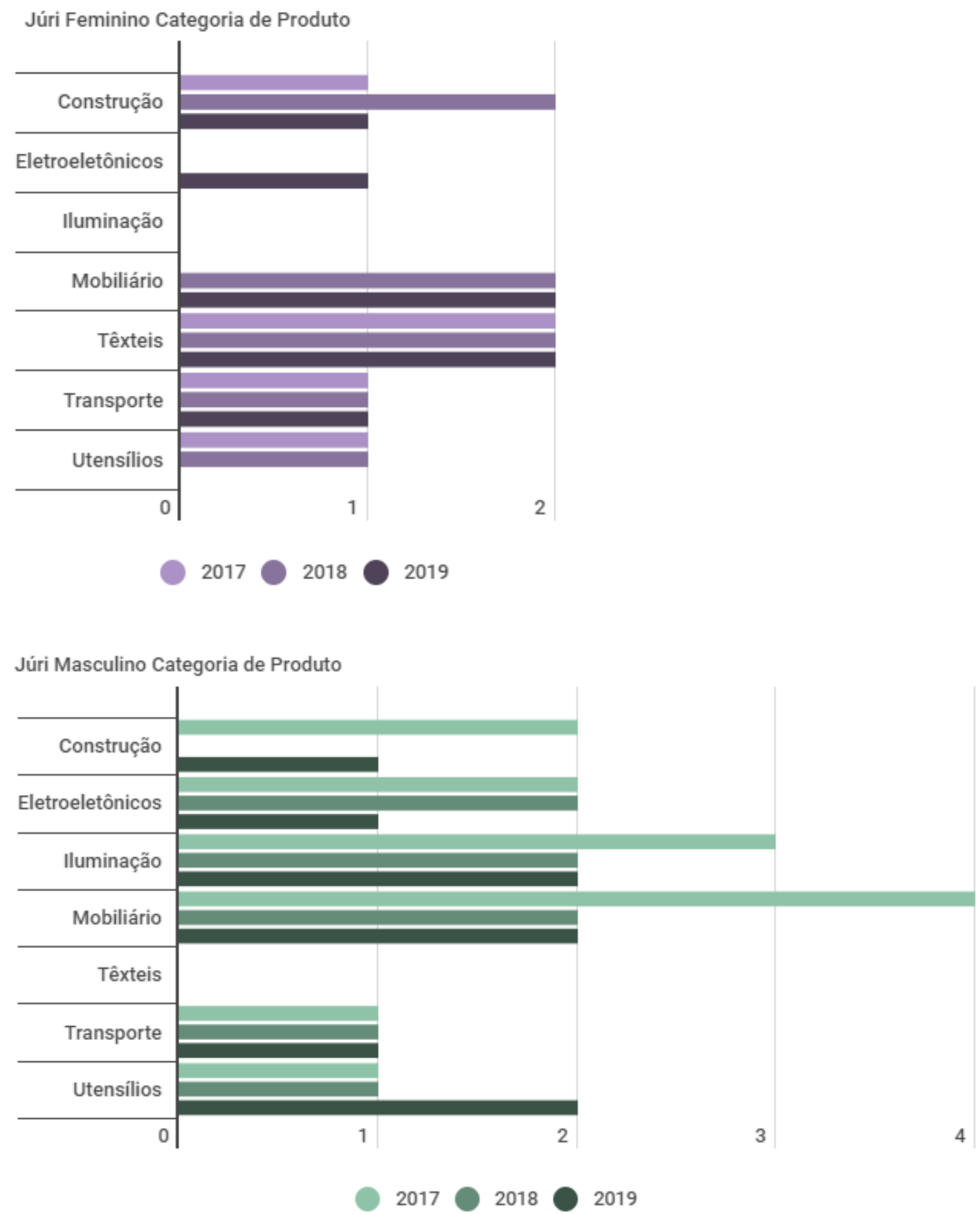

Acerca dos autores dos projetos premiados, os catálogos das edições selecionadas constam em média 248 nomes citados por ano. No Gráfico 4 é possível visualizar a quantidade de nomes femininos e masculinos mencionados, apesar da constante superioridade de homens na premiação, percebemos que a diferença enfraqueceu após o primeiro ano analisado. 


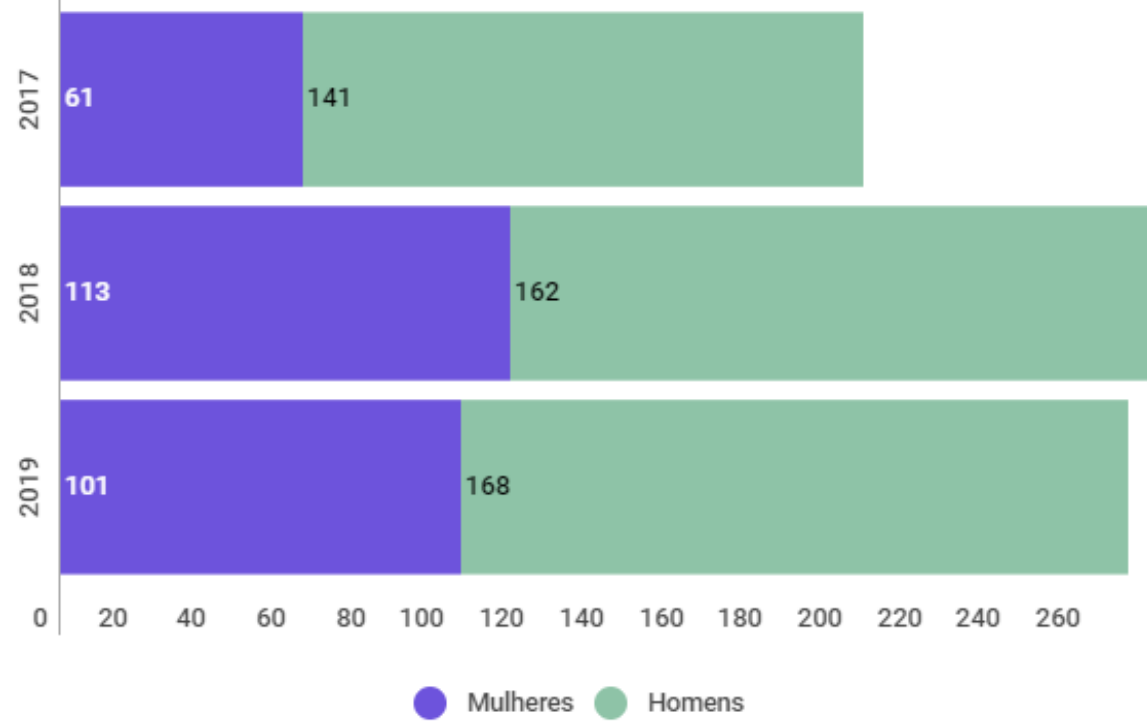

Com relação aos segmentos em que as mulheres aparecem com maior frequência, pensando na totalidade de nomes e desconsiderando as colocações (Exemplo: $1^{\circ}$ Lugar, $2^{\circ}$ Lugar, $3^{\circ}$ Lugar e Menção Honrosa) verifica-se que as únicas categorias em que as mulheres aparecem sempre em maior quantidade do que os homens é a de Trabalhos Escritos e Têxteis. (Tabela 2). Nas demais, esse fato não ocorre, apesar de em alguns momentos ocorrer a proximidade entre o total em outros segmentos. Os setores que apresentam a maior diferença entre os gêneros são: Iluminação, Transportes e Construção. Essas categorias manifestam no decorrer dos anos analisados uma presença de autores masculinos visivelmente superior aos femininos.

Tabela 2 - Nomes citados para cada categoria

\begin{tabular}{l|l|l|l|l|l|l|}
\cline { 2 - 7 } & \multicolumn{2}{c}{2017} & \multicolumn{2}{c|}{2018} & \multicolumn{2}{c|}{2019} \\
\cline { 2 - 7 } & Feminino & Masculino & Feminino & Masculino & Feminino & Masculino \\
\hline Cartaz & 3 & 8 & 4 & 14 & 31 & 32 \\
\hline Construção & 6 & 17 & 9 & 13 & 2 & 13 \\
\hline Eletroeletrônicos & 10 & 15 & 21 & 30 & 15 & 44 \\
\hline Iluminação & 2 & 22 & 6 & 31 & 2 & 14 \\
\hline Mobiliário & 6 & 17 & 16 & 17 & 4 & 28 \\
\hline Têxteis & 5 & 3 & 8 & 7 & 7 & 0 \\
\hline Transporte & 3 & 14 & 1 & 6 & 1 & 11 \\
\hline Utensílios & 10 & 36 & 21 & 28 & 4 & 10 \\
\hline Trab. Escritos & 16 & 9 & 27 & 16 & 35 & 16 \\
\hline TOTAL & 61 & 141 & 113 & 162 & 101 & 168 \\
\hline & & & & & & \\
\hline
\end{tabular}

Considerando o júri selecionado para cada categoria, é possível construir a seguinte relação: as categorias que apresentaram maior percentual feminino no júri como Têxteis e Trabalhos Escritos também apresentam predomínio feminino na autoria do projetos e as categorias que apresentaram maior percentual masculino no júri, como Iluminação e Eletroeletrônicos, também apresentam predomínio masculino no resultado dos projetos selecionados. Todavia, seria precipitado dizer que 
esse fenômeno se refere somente a suposição de que jurados homens escolheriam participantes homens e vice-versa. Esse caso possivelmente reflete uma divisão sexual do trabalho que é vísivel tanto no júri quanto nos participantes premiados. Essa divisão se encontra tão presente em nossa sociedade que muitas vezes não percebemos como a reproduzimos. A escritora Silvia Federici demonstrou muito bem em seu livro o Calibã e a Bruxa: mulheres, corpo e acumulação primitiva (2017) como as mudanças históricas redefiniram a posição das mulheres em relação aos homens na sociedade. Essa segmentação que emergiu e sujeitou as mulheres ao trabalho reprodutivo, também invisibilizou o trabalho realizado no ambiente doméstico sendo mistificado como uma vocação natural e designado como "trabalho de mulheres". Algumas das consequências dessa divisão podem ser observadas no predomínio de mulheres em áreas que se relacionam com o fazer dentro do ambiente doméstico. Assim, faria-se necessário um estudo no futuro amplo a respeito das ocupações de mulheres nestas áreas, postas que não existem no júri ainda representação igualitária. Para compreender se realmente é insólito o número de mulheres com o requisito necessário para compor o juri, ou se existe um tendencionismo para uma escolha de gênero masculino.

Outro ponto a salientar e se aprofundar futuramente no Prêmio é a respeito da representatividade de mulheres negras. Até o momento foi possível constatar o número de mulheres negras que integraram o corpo de jurados nas edições presentes neste estudo. $\mathrm{O}$ resultado mostra que em uma média de 53 jurados por ano, apenas uma era mulher e negra. Essa iniquidade é alarmante e precisa ser questionada, principalmente em um país em que a maior parte da população é negra, quase $56 \%$, o que faz do Brasil a maior nação negra fora da África.(RIBEIRO, 2019). Djamila Ribeiro (2019) aponta também para o risco de convivermos com pessoas de apenas um determinado grupo ou classe social, podendo cair na armadilha de acreditar que só essas pessoas possuem capacidade para determinados cargos, relegando outros grupos a lugares predeterminados, como se não fossem capazes.

Esses resultados transpõem em partes a realidade social em que a área está inserida. Apesar do aumento de mulheres nas premiações, a presença feminina parece expandir com mais facilidade em áreas relacionadas e aceitas como 'trabalho de mulheres'. Vale ressaltar também a maior incidência de pessoas brancas nos prêmios. Esses são temas que exigem maiores estudos e aprofundamentos visando uma prática menos opressiva.

\section{Considerações}

Decorrente do contexto posto, as premiações de design constituem uma significativa fonte de informação e de registro histórico da produção brasileira da área. Também são capazes de dar visibilidade ao campo e aos seus profissionais e evidenciar tanto as soluções encontradas por meio do design para as demandas de um momento da sociedade como as preocupações da área ao longo do tempo. Devido a sua importância no design, se faz relevante questionar e compreender se são espaços de igualdade de gênero para os envolvidos.

Da necessidade de eclodir a questão da representatividade feminina nas premiações de design, contemplamos que a teoria aponta para uma desigualdade vivenciada pelas mulheres nesses espaços, citada por Margaret Bruce (1990) e Alice Hetzel (2016). Ao observamos o Prêmio Design Museu da Casa Brasileira, constatamos que a presença de mulheres tem aumentado no decorrer dos últimos três anos. Todavia, a divisão sexual do trabalho citada ecoa nos resultados da pesquisa, as mulheres são maioria (tanto no júri quanto nas participantes) apenas nos campos que podem ser atrelados ao ambiente doméstico e às características comumente atribuídas ao feminino. Para além do recorte de gênero, ao refletir sobre a raça, essa desigualdade se torna enorme e até o momento constante, como vimos nos resultados do júri. Dentro desta configuração imposta, permite a reflexão sobre novas possibilidades do reconhecer em todas as áreas oferecidas nas premiações sem predestinações a gênero feminino ou masculino, o que contribuiria para o design com maior abrangência.

Dialogando com o pensamento de Burkhardt (1989) sobre museus e exposições que integrem uma afirmação de futuro, precisamos repensar o design que estamos deixando nos nossos registros históricos e exposições. Se o mesmo retrata a sociedade brasileira em sua diversidade e suas reais problemáticas e soluções. Pois quanto mais diversidade nós obtivermos nas entregas de peças e produtos criados pelos profissionais, mais próximo estaremos da realidade do país. Acreditamos que a questão da representatividade não é a solução para todas as problemáticas relacionadas ao gênero, mas 
um caminho que visa um design que não reproduza e perpetue com as contradições da nossa realidade atual, sucedidas por pesquisas que buscam reconhecer como essas desigualdades ocorrem na área.

Female protagonism in the Museu da Casa Brasileira Design Award: analysis of the years between 2017 and 2019

\section{Abstract:}

This article is part of a master's degree research in design that approaches the female protagonism in Brazilian design based on studies of feminism. About the subject, we understand that gender inequality is a social and structural problem present in our society and also. That it manifests itself in the job market in practically all countries around the world in several ways, such as through salary differences, sexual division of labor and multiple female workdays. Thus, inserted in this theme, the article seeks to understand how women interact with design professionally and if the awards in this area represent a challenging environment for these professionals. The method adopted was qualitative and quantitative, with application of a bibliographical review and a case study. The Design Museu da Casa Brasileira Award (2017-2019) was selected as a sample for assessing women's presence among the authors and jurors at the awards. In this sense, it was found that the number of women in these spaces has been growing, however, it is still possible to verify some deadlocks for the female public.

Keywords: Design; Feminine Protagonism; Awards; Brazil

\section{Referências bibliográficas}

ANDRADE, Ana Beatriz P.; REBELLO, Ana Maria. A invisibilidade feminina no design: da Bauhaus ao Brasil. In: Tercer Encuentro Latinoamericano de Diseño. Conferência da Universidade de Palermo, Buenos Aires, Argentina, 2008.

ASSOCIAÇÃO OBJETO BRASIL. Um olhar sobre o design. São Paulo: SENAI-SP editora, 2012. BEAUVOIR, Simone. O segundo sexo: fatos e mitos. Difusão Europeia do Livro, 1970.

BRUCE, Margaret. A missing link: women and industrial design. Design Studies, v.6, n.3, 1985, p.10156.

BRUCE, Margaret. Women designers is there a gender trap? Design Studies, v. 11, n.2, 1990, p. 114-120.

BUCKLEY, Cheryl. Made in Patriarchy: Toward a Feminist Analysis of Women and Design. Design Issues, v. 3, n. 2, p.3-14, 1986.

CAMPI, I. El sexo determina La historiac Las diseñadoras de produto: um estado de La cuestión. In: Deseño y Historia: tiempo, lugar y discurso. (pp. 87-114). Mexico: Designio, 2010.

CARNASCIALI, R. M. (2014). Gestão de design: contribuições da gestão da qualidade para a construção de parâmetros para avaliar o bom design (Dissertação de mestrado). Universidade Federal do Paraná, Curitiba.

FEDERICI, Silvia. Calibã e a Bruxa: mulheres, corpo e acumulação primitiva. São Paulo: Elefante, 2017.

Guia de enfrentamento do racismo institucional. Disponível em: <http://www.onumulheres.org.br/wpcontent/uploads/2013/12/Guia-de-enfrentamento-ao-racismo-institucional.pdf > Acesso em: 10 de ago. 2020.

HETZEL, A. D. Mulheres no Design Gráfico: O passado e presente - uma análise comparada entre Brasil e Portugal. Dissertação (mestrado). Lisboa: Universidade de Lisboa, 2016. 
KIRKHAM, Pat. In a Man's World" Women Industrial Designers. In: Women Designers in the USA, 1900-2000. New Haven and London: Yale University Press, p. 269 - 290. Disponível em: https://www.bgc.bard.edu/gallery/exhibitions/51/women-designers-in-the-usa.

LEAL, J. J. A importância dos prêmios de design. Info paper no. 8, SENAI São Paulo Design, 2010.

LEON, E. Design em exposição: o design no Museu de Arte Moderna no Rio de Janeiro (1968-1978), na Federação das Indústrias de São Paulo (1978-1984) e no Museu da Casa Brasileira (1986- 2002) (Tese de doutorado). Universidade de São Paulo, São Paulo, 2012.

MOURA, Mônica. Design contemporâneo: poéticas da diversidade no cotidiano. In: FIORIN, Evandro;LANDIM, Paula da Cruz; LEOTE, Rosangela da Silva (Org.). Arte-ciência: processos criativos. São Paulo: Cultura acadêmica, 2015.

PETRUCCELLI, José Luís; SABOIA, Ana Lucia. (Orgs.) Características Étnico-Raciais da População: Classificação e Identidades. IBGE - Rio de Janeiro, 2013.

RIBEIRO, Djamila. Pequeno Manual Antirracista. São Paulo: Companhia das Letras, 2019.

SAFAR, G.; ALMEIDA, M.G. Protagonismo feminino no design - um resgate histórico em andamento. In: DE MORAES, D.; DIAS, R. A.; BOM CONSELHO, R. (Org.) Cadernos de Estudos Avançados em Design - História. Barbacena: Universidade do Estado de Minas Gerais, 2014.

SCHNEIDER, Beat. Design - uma introdução: O design no Contexto Social, Cultural e Econômico. Editora Blucher, 2010.

VADILLO, M. El triunfo de las diseñadoras invisibles: la Bauhaus em femenino. I+Diseño: revista internacional de investigación, innovación y desarrollo en diseño, 1(1), 27-34, 2009. 